\title{
IGF1-induced AKT phosphorylation and cell proliferation are suppressed with the increase in PTEN during luteinization in human granulosa cells
}

\author{
Maki Goto ${ }^{1}$, Akira Iwase ${ }^{1,2}$, Toko Harata ${ }^{1,2}$, Sachiko Takigawa ${ }^{1}$, Kyosuke Suzuki ${ }^{1}$, \\ Shuichi Manabe ${ }^{1}$ and Fumitaka Kikkawa ${ }^{1}$ \\ Departments of ${ }^{1}$ Obstetrics and Gynecology and ${ }^{2}$ Maternal and Perinatal Medicine, Nagoya University Graduate \\ School of Medicine, 65 Tsurumai-cho, Showa-ku, Nagoya 466-8550, Japan
}

Correspondence should be addressed to A Iwase; Email: akiwase@med.nagoya-u.ac.jp

\begin{abstract}
Granulosa cells proliferate and then undergo differentiation; an inverse relationship between these processes is observed during terminal follicular growth. During terminal follicular growth and initial luteinization, there is a necessary transition of granulosa cells to a less proliferative and highly steroidogenic form in response to LH. Although the expression of several molecules has been reported to be up-regulated by LH, proliferation/differentiation transition is not fully understood. Here, we show that the expression of a tumor suppressor, phosphatase and tensin homologue deleted on chromosome 10 (PTEN) was induced with human chorionic gonadotropin (hCG) treatment in human luteinized granulosa cells. Pretreatment with hCG attenuated insulin-like growth factor (IGF)-1-induced phosphorylation of AKT and cell proliferation, not phosphorylation of ERK1/2. Moreover, suppression of hCG-induced PTEN expression with siRNA increased AKT phosphorylation and cell proliferation in response to IGF1. We also demonstrate that a PI3K inhibitor, LY294002, not a MEK inhibitor, PD98059, inhibited IGF1-induced cell proliferation. In conclusion, PTEN induced to express by hCG in luteinized granulosa cells that inactivates AKT, not ERK, and attenuates IGF1-induced cell proliferation. PTEN expression may be a trigger for proliferation/differentiation transition in human granulosa cells.

Reproduction (2009) 137 835-842
\end{abstract}

\section{Introduction}

The maturation of oocytes is under the regulatory control of signals from proliferating granulosa cells, in response to stimulation by gonadotropin and growth factors (Moor et al. 1998). Although, FSH plays the most significant role in the folliculogenesis in post-secondary stages of follicle development, several studies have shown the involvement of insulin-like growth factor (IGF)-1 in the survival of granulosa cells in humans (Poretsky et al. 1999, Bencomo et al. 2006) and other species (Guthrie et al. 1998, Johnson et al. 2001, Quirk et al. 2004) to be comparable with that of FSH. The biological functions of IGF1 are mainly mediated by the type-I IGF receptor (IGF1R), which is able to activate the phosphatidylinositol 3-kinase (PI3K)/AKT pathway (Roberts 1996). PI3K generates phosphatidylinositol3,4,5-triphosphate (PIP3), which activates multiple downstream effectors including AKT, by phosphorylating phosphatidylinositol-4,5-biphosphate (PIP2; Cantley \& Neel 1999). Such activation is correlated with cell survival in a wide variety of cells, including those of epithelial, mesenchymal, and neuronal origin (Datta et al. 1997, Kulik et al. 1997), as well as cancer cells (Sumitomo et al. 2004). In bovine granulosa cells, AKT, a downstream substrate of PI3K, was necessary for the protective effect of IGF1 against FASL-induced apoptosis (Hu et al. 2004). AKT has also been demonstrated to be involved in granulosa cell survival in hens (Johnson et al. 2001) and pigs (Westfall et al. 2000).

During terminal follicular growth and initial luteinization, granulosa cells change to a less proliferative and highly steroidogenic form in response to $\mathrm{LH}$, which is the trigger of ovulation and luteinization. The expression of a wide spectrum of genes has been demonstrated to be modulated by LH (Rimon et al. 2004, Sasson et al. 2004), which may affect changes induced by FSH and/or IGF1 and cause maturation of granulosa cells. However, the mechanism of this LH-responsive differentiation/maturation has not been entirely revealed.

Phosphatase and tensin homologue deleted on chromosome 10 (PTEN) lipid phosphatase antagonizes the activity of PI3K by dephosphorylating PIP3 to PIP2 (Maehama \& Dixon 1998). Therefore, PTEN indirectly 
inhibits the phosphorylation of AKT and its activation or inactivation results in decreased or increased AKT activity (Leslie \& Downes 2004). Originally, PTEN was reported to be a tumor suppressor frequently inactivated in a number of cancers including prostate, brain, and endometrial cancer. Recently, alterations in the expression and activity of PTEN have been proposed to play a causal role in the development of several conditions other than cancer, including rheumatoid arthritis, chronic obstructive pulmonary disease, and pulmonary fibrosis (Anderson \& Bozinovski 2003, White et al. 2003). Theoretically, the balance between PI3K and PTEN determines PIP3 levels, which affect a variety of intracellular signals, such as AKT. Recently, we have reported that PTEN expression becomes intense during follicular growth, whereas the intensity of phospho-AKT becomes weak in granulosa cells, which suggests PTEN to be involved in the regulation of proliferation and differentiation of granulosa cells in human ovary via modulation of the PI3K/AKT pathway (Goto et al. 2007).

Therefore, the aim of the present study was to test the hypothesis that PTEN expression is induced during luteinization and affects granulosa cell proliferation via dephosphorylation of AKT. We also investigated the contrast in signaling pathways between AKT and ERK.

\section{Results}

Induction of PTEN expression with human chorionic gonadotropin in primary cultured luteinized granulosa cells

We first performed western blotting and real-time RT-PCR using primary cultured luteinized granulosa cells to assess the expression and induction of PTEN with human chorionic gonadotropin (hCG) stimulation. Western blotting showed that luteinized granulosa cells expressed PTEN, which was up-regulated with hCG in a dose-dependent manner (Fig. 1A) and in a time course up to $48 \mathrm{~h}$ (Fig. 1B). Real-time RT-PCR showed an $\sim 1.7$-fold increase in the level of PTEN mRNA with 1 or $10 \mathrm{lU} / \mathrm{ml}$ hCG (Fig. 1C).

\section{Inhibition of IGF1-induced AKT phosphorylation, but not ERK phosphorylation, by hCG pretreatment}

We next explored the signaling pathways downstream of IGF1 in luteinized granulosa cells with or without hCG pretreatment. IGF1 induced phosphorylation of AKT and ERK1/2 without hCG pretreatment. ERK1/2 was slightly phosphorylated with hCG treatment, while AKT was not phosphorylated with hCG. Pretreatment with hCG induced expression of PTEN and inhibited IGF1-induced phosphorylation of AKT, but not ERK1/2. Expression of IGF1R was not affected by hCG (Fig. 2).
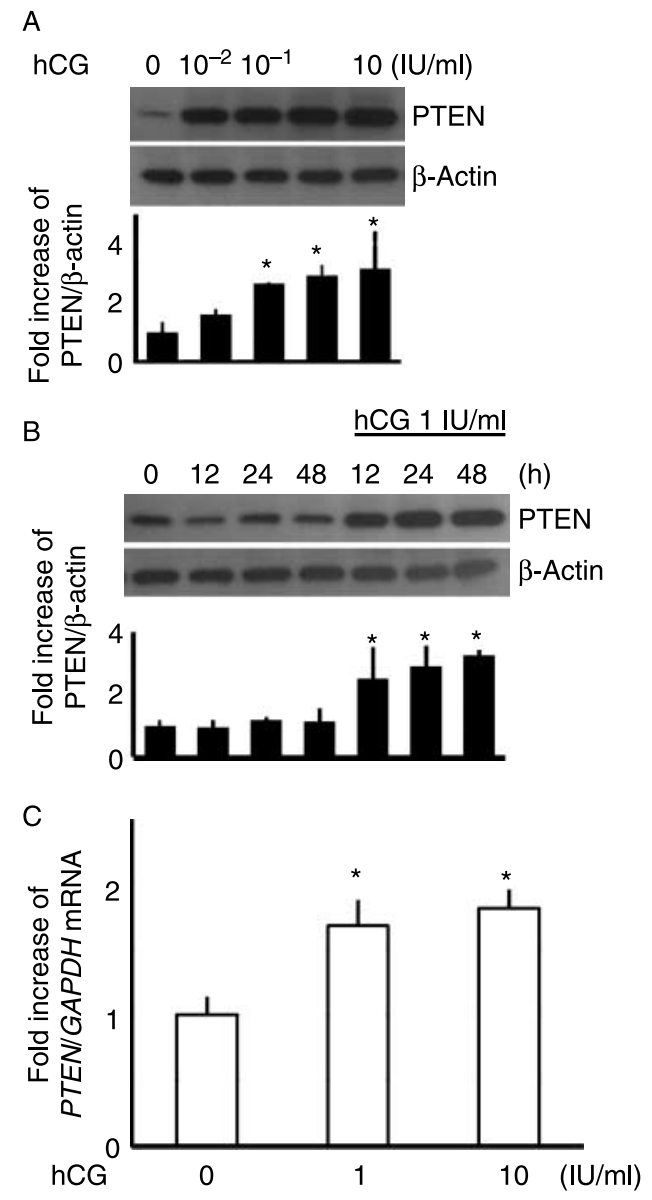

Figure 1 (A) Dose-dependent increase of PTEN in primary cultured luteinized granulosa cells stimulated with hCG for $48 \mathrm{~h}$. (B) Time course of the increase in PTEN in primary cultured luteinized granulosa cells treated with or without $1 \mathrm{IU} / \mathrm{ml}$ hCG. A $10 \mu \mathrm{g}$ sample was subjected to SDS-PAGE and immunoblotting using anti-PTEN Ab (top) or anti- $\beta$-actin $A b$ as an internal control (middle). Densitometric analysis of protein levels of PTEN (bottom). Protein contents in the three different sets of samples were quantified and normalized by $\beta$-actin signals. PTEN/ $\beta$-actin before stimulation was regarded as control. (C) Real-time PCR for PTEN. Total RNA was isolated from primary cultured luteinized granulosa cells without hCG or with 1 or $10 \mathrm{IU} / \mathrm{ml}$ hCG for $24 \mathrm{~h}$. PTEN/GAPDH before stimulation was regarded as control. Western blotting and quantitative PCR showed that hCG induced expression of PTEN in luteinized granulosa cells. Data were analyzed using repeated measures of ANOVA; shown are represent the mean \pm s.D. of three independent replicates. Dunnett's post-test was used to compare each dose or time point with the control. ${ }^{*} P<0.05$ (vs control).

\section{Inhibition of IGF1-induced cell proliferation}

Recent studies demonstrated that IGF1 stimulates proliferation of granulosa cells via the PI3K/AKT pathway (Westfall et al. 2000, Hu et al. 2004). Therefore, we examined whether IGF1 stimulates proliferation of human luteinized granulosa cells and whether hCG affects IGF1-induced cell proliferation. 


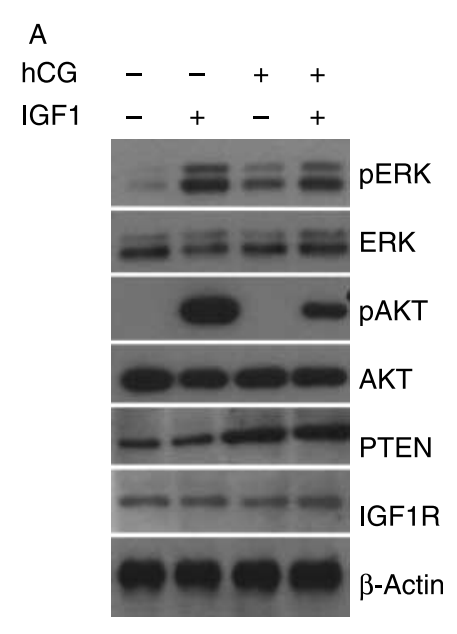

B

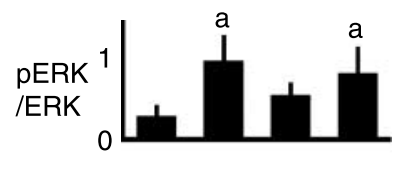

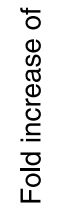
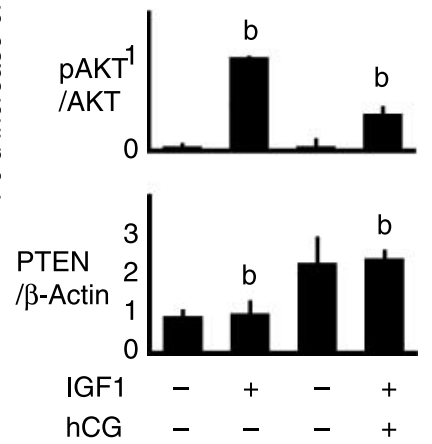

Figure 2 (A) Phosphorylation of AKT and ERK1/2 in primary cultured luteinized granulosa cells. Cells without hCG-pretreatment were cultured with (lane 2) or without (lane 1) $10 \mathrm{ng} / \mathrm{ml} \mathrm{IGF1} \mathrm{for} 10 \mathrm{~min}$. Cells pretreated with hCG for $24 \mathrm{~h}$ were cultured similarly with (lane 4) or without (lane 3) IGF1. IGF1 induced the phosphorylation of AKT and ERK1/2 in the cells not pretreated with hCG (lane 2). Pretreatment with hCG attenuated the IGF1-induced phosphorylation of AKT, but not ERK1/2, in the cells which expressed higher levels of PTEN (lane 4). Constant expression of IGF1 receptor (IGF1R) was confirmed. Three independent experiments gave similar results. (B) Densitometric analysis of western blotting. Protein contents in the three different sets of samples were quantified and normalized by $\beta$-actin (PTEN), AKT (pAKT), and ERK (pERK) signals. Signals with IGF1 stimulation without hCG-pretreatment were regarded as control. Data were analyzed using repeated measures ANOVA; shown are to represent the mean \pm s.D. of four independent replicates. Dunnett's post-test was used to compare each treatment with the control. ${ }^{a}$ no significant difference, ${ }^{b} P<0.05$.

A bromodeoxyuridine (BrdU) cell proliferation assay revealed that IGF1 induced DNA synthesis in luteinized granulosa cells without hCG pretreatment, which was inhibited by LY294002, but not PD98059. Pretreatment with hCG abolished the IGF1-induced cell proliferation (Fig. 3).

\section{Recovery of IGF1-induced AKT phosphorylation using siRNA for the suppression of PTEN expression}

Finally, we explored the effect of inhibition of hCGup-regulated-PTEN. Luteinized granulosa cells transiently transfected with siRNA for PTEN showed the suppression of PTEN expression and a recovery of the phosphorylation of AKT with IGF1 (Fig. 4). A BrdU cell proliferation assay revealed that hCG-inhibited DNA synthesis in response to IGF1 stimulation was partially recovered in luteinized granulosa cells with knock down of endogenous PTEN (Fig. 5).

\section{Discussion}

In the present study, we demonstrated that PTEN induced to express by hCG in luteinized granulosa cells attenuates AKT phosphorylation and therefore has an anti-proliferative effect. In addition, we recently reported that granulosa cells in large preovulatory follicles expressed higher levels of PTEN than granulosa cells in small follicles showing negligible or occasional staining, suggesting that PTEN expression increases during terminal follicular growth. We also demonstrated that the immunohistochemistry for serial sections showed an inverse relationship between PTEN and phospho-AKT.

IGF1 is undoubtedly significant for folliculogenesis. Female IGF1-null mutant mice fail to ovulate and lack corpora lutea (Baker et al. 1996). Slot et al. (2006) recently demonstrated that IGF1 treatment results in an increased number of healthy antral follicles with a decreased percentage of atretic follicles in $\mathrm{GH}$ receptor knock-out mice, which show a decrease in healthy growing follicles and an increase in atretic follicles compared with wild-type. In bovine granulosa cells, AKT is involved in the cell survival under IGF1 stimulation (Hu et al. 2004). Granulosa cells proliferate and then undergo differentiation, an inverse relationship between the processes being observed during terminal follicular growth (Monniaux \& Pisselet 1992). In this regard, suppressive effects on the IGF1/AKT pathway are speculated to be important to differentiate following proliferation of granulosa cells and maintain steroidogenesis. Our results suggest the possible involvement of PTEN, which increases in expression with $\mathrm{LH} / \mathrm{hCG}$ stimulation during terminal follicular development, in the regulation of proliferation and differentiation of granulosa cells to maintain a luteinized state.

We also found that two signaling pathways downstream of IGF1, the AKT and ERK pathways, possess different effects and regulatory mechanisms. Ryan et al. (2007) recently reported that both pathways, which are important for dominant follicle selection, show several differences in their expression profile in cattle follicles. However, few reports have investigated differences between the AKT and ERK pathways in expression, effects, and regulation in granulosa cells. 

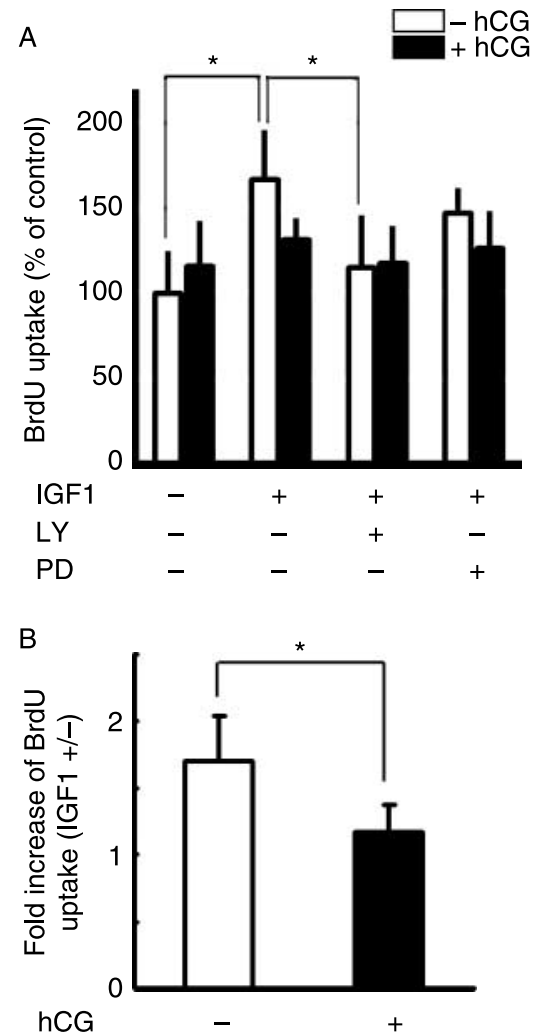

Figure 3 (A) BrdU proliferation assay. Primary cultured luteinized granulosa cells with (black bars) or without (white bars) pretreatment using $1 \mathrm{IU} / \mathrm{ml}$ hCG for $24 \mathrm{~h}$ were cultured with $10 \mathrm{ng} / \mathrm{ml} \mathrm{IGF1,} \mathrm{with} \mathrm{or}$ without $10 \mu \mathrm{M}$ LY294002 (LY) or $100 \mu \mathrm{M}$ PD98059 (PD) for $24 \mathrm{~h}$. The incorporation of $\mathrm{BrdU}$ was measured using an ELISA system. $\mathrm{BrdU}$ uptake with no treatment was regarded as control. Without hCG-pretreatment, IGF1 induced DNA synthesis in the cells, which was inhibited by LY294002 but not PD98059 (white bars). Pretreatment with hCG attenuated the IGF1-induced DNA synthesis (black bars). Data were analyzed using repeated measures of ANOVA; shown are to represent the mean \pm s.D. of three independent replicates. Bonferroni correction was used to compare all pairwise. ${ }^{*} P<0.05$. (B) BrdU proliferation assay comparing fold increase by IGF1 stimulation between cells with (black bars) and without (white bars) pretreatment using $1 \mathrm{IU} / \mathrm{ml}$ hCG for $24 \mathrm{~h}$. Data were analyzed using paired $t$-test; shown are represent the mean \pm s.D. of three independent replicates. $* P<0.05$.

We demonstrated that granulosa cell proliferation under IGF1 stimulation are dominantly mediated by the AKT, not ERK, pathway. We also found that ERK, not AKT, is phosphorylated with continuous hCG stimulation. Seto-Young et al. (2003) demonstrated that PD98059 attenuated IGF-induced progesterone production in human granulosa cells. Taken together, the PI3K/AKT pathway downstream of IGF1 might be dominantly involved in granulosa cell proliferation, whereas the ERK pathway downstream IGF1 and hCG may be implicated in steroidogenesis. Granulosa cells adopt a less proliferative and highly steroidogenic form in response to LH during terminal follicular growth and initial luteinization. In support of this point of view, our results show that LH/hCG-induced expression of PTEN affects the
PI3K/AKT pathway involved in proliferation, not the MAP kinase/MEK/ERK pathway dominantly involved in steroidogenesis under IGF1 and hCG stimulation (Fig. 6). However, inhibition of the ERK pathway with PD98059 attenuated $\mathrm{FSH}$-stimulated survival in porcine granulosa cells (Shiota et al. 2003). The whole picture concerning ERK pathways downstream of factors such as FSH is yet to be fully revealed.

Stimulation with LH of matured preovulatory follicles induces the differentiation of granulosa cells into luteinized granulosa cells (Richards et al. 2002). It has been demonstrated that several molecules that are up-regulated with LH stimulation are involved in granulosa cell differentiation and luteinization. Our findings indicate that PTEN is one such molecule. However, our results showed that DNA synthesis in response to IGF1 stimulation was partially recovered in
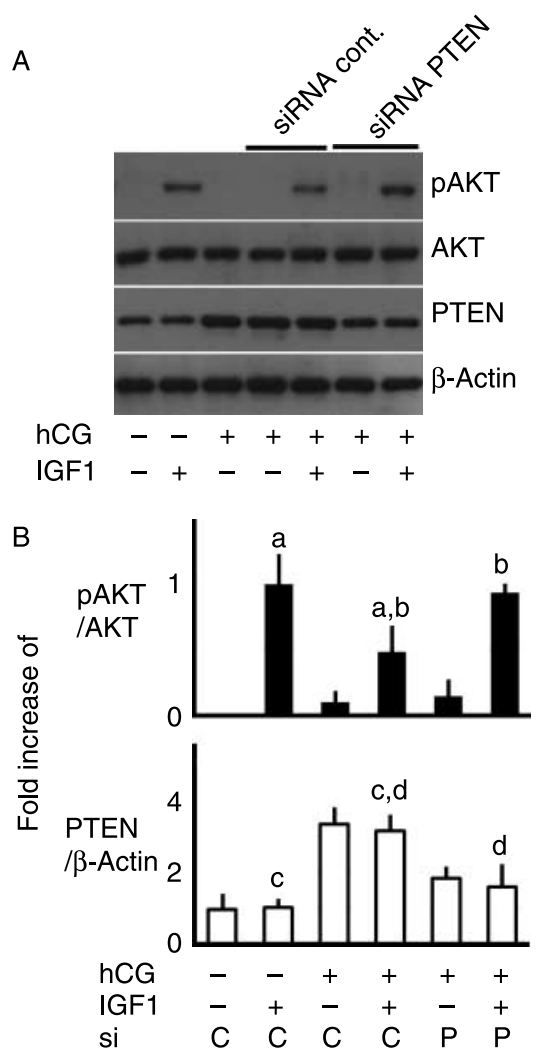

Figure 4 (A) AKT phosphorylation with IGF1 was increased with inhibition of PTEN expression using siRNA. Expression of PTEN in hCG-treated luteinized granulosa cells was inhibited by siRNA for PTEN (lane 6 and 7), but not control siRNA (lane 4 and 5).

Phosphorylation of AKT was promoted in luteinized granulosa cells transfected with siRNA for PTEN prior to stimulation with IGF1, which resulted in the suppression of PTEN expression induced with hCG.

(B) Densitometric analysis of western blotting. Protein contents in the three different sets of samples were quantified and normalized by $\beta$-actin (PTEN) and AKT (pAKT) signals. Signals with IGF1 stimulation without hCG-pretreatment were regarded as control. C, control siRNA; P, PTEN siRNA. Data were analyzed using repeated measures ANOVA; shown are to represent the mean \pm s.D. of three independent replicates. Bonferroni correction was used to compare all pairwise. ${ }^{\mathrm{a}, \mathrm{b}, \mathrm{c}, \mathrm{d}} \mathrm{P}<0.05$. 


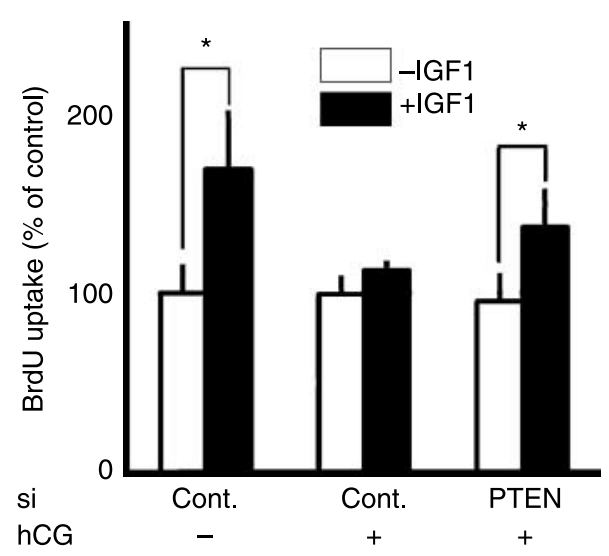

Figure $5 \mathrm{BrdU}$ proliferation assay. siRNA-transfected luteinized granulosa cells with or without pretreatment using $1 \mathrm{IU} / \mathrm{ml} \mathrm{hCG}$ for $24 \mathrm{~h}$ were cultured with (black bars) or without (white bars) $10 \mathrm{ng} / \mathrm{ml}$ IGF1 for $24 \mathrm{~h}$. The incorporation of BrdU was measured using an ELISA system. Knock down of endogenous PTEN attenuated inhibition of DNA synthesis in response to IGF1 with hCG pretreatment. Data were analyzed using paired $t$-test; shown are to represent the mean \pm s.D. of four independent replicates. ${ }^{*} P<0.05$.

luteinized granulosa cells with knock down of endogenous PTEN. The process of luteinization is so complicated that any single molecule including PTEN can not regulate luteinization completely. Another reason may be the efficiency of knock-down of PTEN.

We used luteinizing granulosa cells in the present study. To estimate the gonadotropin effects more clearly, non-luteinizing granulosa cells obtained at gynecologic surgery would be more appropriate; however, it is very difficult to use abundant human undifferentiated granulosa cells before LH/hCG stimulation for in vitro experiments. KGN (immortalized cells derived from granulosa cell tumor) have sometimes been used instead of primary cultured granulosa cells. KGN might possess steroidogenesis similar to normal granulosa cells;
A

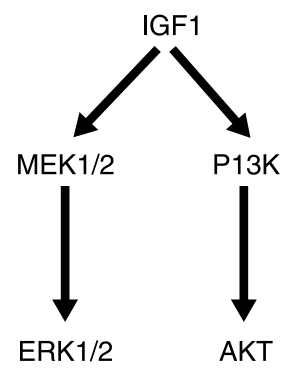

B

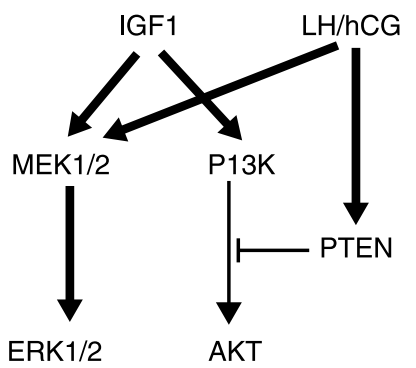

Figure $6 \mathrm{~A}$ model for the role of PTEN as a switch of luteinization in human granulosa cells. (A) In granulosa cells without LH/hCG stimulation, IGF1 induces steroidogenesis and cell proliferation via MEK/ERK1/2 and PI3K/AKT pathways. (B) Dephosphorylation of AKT with PTEN induced by LH/hCG abolishes cell proliferation stimulated with IGF1 in luteinizing granulosa cells. Steroidogenesis may be maintained with MEK/ERK1/2 pathway stimulated with IGF1 and LH/hCG. however, it is probable that KGN has different proliferative potential from normal granulosa cells because $\mathrm{KGN}$ is a tumor-derived cell line. Granulosa cells obtained from animal ovaries have been used when human undifferentiated granulosa cells were difficult to obtain. Although it is an option, the process and regulation of folliculogenesis may differ in different species, thus, there is a limitation to the use of animal granulosa cells, hence we used luteinizing granulosa cells. Luteinizing is a process that forms a corpus luteum under LH/hCG stimulation; therefore, luteinizing granulosa cells in culture just after oocyte retrieval may possess characteristics of undifferentiated-differentiated transition of granulosa cells. Further studies using undifferentiated granulosa cells, including immortalized human cells, are required to reveal the mechanism and process of luteinization of human granulosa cells under gonadotropin and growth factor stimulation.

Several circumstances have now been identified in which PTEN expression is transcriptionally regulated (Leslie \& Downes 2004). The response of granulosa cells to $\mathrm{LH}$ is mediated mainly by CAMP/protein kinase $\mathrm{A}$ signaling. LH/hCG has also been shown to stimulate phospholipase C and ERK (Gudermann et al. 1992, Das et al. 1996). In the present study, real-time PCR showed that mRNA of PTEN increased with hCG stimulation. Therefore, there is a possibility that these signaling molecules transcriptionally regulate PTEN expression in granulosa cells. The regulatory mechanism of PTEN expression under hormonal stimulation even in other cells has not been well investigated. Guzeloglu-Kayisli et al. (2003) have reported that the PTEN pool is regulated by decreasing phosphorylation with progesterone in human endometrial cells. Phosphorylation of PTEN is implicated in the activation and stabilization of PTEN itself (Gericke et al. 2006). Further studies are required to reveal how the expression of PTEN is regulated by hormonal stimulation during terminal follicular growth and luteinization as well as its phosphorylation status.

Froment et al. (2005) has recently demonstrated that PTEN levels increase during terminal follicular growth in ovine granulosa cells. However, in their experiments, $\mathrm{LH}$ did not induce PTEN expression in vitro. The discrepancy with our results regarding the induction of PTEN expression with LH/hCG might be due to the luteinization status of granulosa cells as well as difference of species, regardless of the similar immunohistochemical findings for ovaries.

In conclusion, we demonstrated that PTEN induced to express hCG in luteinized granulosa cells attenuates phosphorylation of AKT, not ERK, and attenuates IGF1induced cell proliferation. Interestingly, such an increase in PTEN expression has been shown in the proliferation/differentiation transition of human endometrial cells (Mutter et al. 2000). Therefore, our findings suggest PTEN expression to be one of the triggers for proliferation/differentiation transition in human granulosa cells. 
Further studies are required to make a detailed evaluation in function and regulation of PTEN in human ovaries.

\section{Materials and Methods Isolation and culture of luteinized granulosa cells}

Human luteinized granulosa cells were collected from follicular fluid obtained via ultrasound-guided transvaginal oocyte retrieval as previously described (Goto et al. 2007). Briefly, the luteinized granulosa cells after isolation of the oocytes were separated from red blood cells with a Percoll gradient (Amersham Biosciences Corp.) and resuspended in DMEM (Sigma) containing 10\% FCS (Sigma), $100 \mathrm{IU} / \mathrm{ml}$ penicillin, $100 \mu \mathrm{g} / \mathrm{ml}$ streptomycin, $25 \mathrm{mg} / \mathrm{l}$ amphotericin B, and L-glutamine. Then luteinized granulosa cells were seeded onto a $35 \mathrm{~mm}$ sterile collagen-coated dish (Biocoat; Becton Dickinson and Co., Franklin Lakes, NJ, USA) or a 4-well chamber slide (Lab-Tek Chamber Slide; Nalge Nunc International, Rochester, NY, USA). This study was approved by the Ethics Committee of Nagoya University Graduate School of Medicine. Informed consent was obtained from patients.

\section{Western blotting for PTEN with hCG stimulation}

Primary cultured luteinized granulosa cells were lysed in RIPA buffer $(10 \mathrm{mM}$ Tris- $\mathrm{HCl}$, pH 7.4, $150 \mathrm{mM} \mathrm{NaCl}, 1 \%$ Nonidet P-40, 5 mM EDTA, 1\% sodium deoxycholate, 0.1\% SDS, 1.2\% aprotinin, $5 \mu \mathrm{M}$ leupeptine, $4 \mu \mathrm{M}$ antipain, $1 \mathrm{mM}$ phenylmethylsulfonylfluoride, and $0.1 \mathrm{mM} \mathrm{Na}_{3} \mathrm{VO}_{4}$ ) after treatment with various concentrations of hCG for 12, 24 or $48 \mathrm{~h}$. Cell lysates were clarified by centrifugation at $13000 \mathrm{~g}$ for $15 \mathrm{~min}$ at $4{ }^{\circ} \mathrm{C}$ and diluted in a $2 \times$ sample buffer $(125 \mathrm{mM}$ Tris- $\mathrm{HCl}$, $\mathrm{pH} 6.8,4 \%$ SDS, $10 \%$ glycerol, $0.2 \%$ bromphenolblue, and $4 \%$ 2-mercaptoethanol). The protein extract $(10 \mu \mathrm{g})$ was separated by $10 \%$ SDS-PAGE, and transferred to a nitrocellulose membrane. After blocking in PBS containing 5\% skim milk for $1 \mathrm{~h}$, the membranes were immunoblotted with anti-human PTEN Ab (A2B1; Santa Cruz Biotechnology, Inc., Santa Cruz, CA, USA; $1: 1000$ ) or anti- $\beta$-actin Ab (Santa Cruz Biotechnology, Inc.). Immunoreactive proteins were stained using an ECL system (Amersham Biosciences). Relative band density normalized by $\beta$-actin was determined from light scans of the resulting films using densitometric analysis software.

\section{RNA extraction and quantitative RT-PCR}

Total RNA was isolated from luteinized granulosa cells in $35 \mathrm{~mm}$ dishes using RNeasy Mini Kit (Qiagen Inc.) following the manufacturer's directions. An RT reaction with $1 \mu \mathrm{g}$ of total RNA was carried out with a first strand cDNA synthesis kit (ReverTra Ace $\alpha$; Toyobo Co., Ltd, Osaka, Japan). Thereafter, real-time PCR was performed in 96-well $0.2 \mathrm{ml}$ thin-wall PCR plates using the Thermal Cycler Dice (Takara Bio Inc., Tokyo, Japan) and SYBR Premix Ex Taq (Takara Bio Inc.). The real-time PCR mixture contained $1 \times$ SYBR Premix Ex Taq, $10 \mu \mathrm{M}$ PCR primers and $1 \mu \mathrm{g}$ CDNA in a total volume of $25 \mu$ l. The following sets of oligonucleotide primers were used: PTEN, 5'-TGACAATCATGTTGCAGCAATTC-3' (sense) and 5'-CACCAGTTCGTCCCTTTCCA-3' (antisense), which correspond to 1376-1398 and 1409-1428 of PTEN cDNA (accession number NM_000314) respectively; GAPDH, 5'-CGGGAAACTGTGGCGTGAT-3' (sense) and 5'-ATGCCAGTGAGCTTCCCGT-3' (antisense), which correspond to 679-696 and 776-794 of GAPDH cDNA respectively. The PCR profile was an initial incubation at $95{ }^{\circ} \mathrm{C}$ for $10 \mathrm{~s}$ followed by 40 cycles with denaturation at $95^{\circ} \mathrm{C}$ for $5 \mathrm{~s}$, and annealing and extension at $60^{\circ} \mathrm{C}$ for 30 .

\section{Phosphorylation of AKT and ERK1/2 with IGF1}

For the detection of phosphorylated AKT and ERK1/2, luteinized granulosa cells with or without hCG-pretreatment were cultured in DMEM without FCS. Then, the cells were stimulated with $100 \mathrm{ng} / \mathrm{ml} \mathrm{IGF1} \mathrm{(Sigma)} \mathrm{for} 10 \mathrm{~min}$. The cells were lysed, resolved by $10 \%$ SDS-PAGE and transferred as described above. Membranes were immunoblotted with anti-AKT Ab (Santa Cruz Biotechnology, Inc.; 1:500), anti-phospho-AKT Ab (Ser 473; New England BioLabs Inc., Ipswich, MA, USA; 1:1,000), anti-ERK1/2 Ab (C-14; Santa Cruz Biotechnology, Inc.; 1:1000), anti-phospho-ERK1/2 Ab (E-4; Santa Cruz Biotechnology, Inc.; 1:1000), or anti-IGF1R Ab (Ab-5; Lab Vision Corp., Fremont, CA, USA).

\section{BrdU cell proliferation assay}

The rate of DNA synthesis was determined from the incorporation of BrdU into cells (BrdU Cell Proliferation Assay; Oncogene Research Products, San Diego, CA, USA) according to the manufacturer's instruction as previously described (Iwase et al. 2006). Briefly, luteinized granulosa cells were seeded at $1 \times 10^{4}$ on a 96-well microplate, treated using $1 \mathrm{IU} / \mathrm{ml} \mathrm{hCG}$ for $24 \mathrm{~h}$, and then cultured with or without $100 \mathrm{ng} / \mathrm{ml}$ IGF1 for the following $24 \mathrm{~h}$ to allow BrdU incorporation. LY294002 (PI3K inhibitor, Promega Corporation), PD98059 (MEK inhibitor, Promega) were added $2 \mathrm{~h}$ prior to IGF1. After fixation, the cells were incubated with anti$\mathrm{BrdU}$ antibody for $1 \mathrm{~h}$, followed by HRP-conjugated goat antimouse IgG. Then, $100 \mu \mathrm{l}$ substrate (tetramethylbenzidine) was added to each well after washing and incubated at room temperature for $30 \mathrm{~min}$. The absorbance at dual wave lengths of $450-540 \mathrm{~nm}$ was determined using the microplate reader.

\section{SIRNA}

siRNA for PTEN was purchased from New England BioLabs (PTEN ShortCut siRNA Mix). Luteinized granulosa cells pretreated with hCG for $24 \mathrm{~h}$ were transfected by siRNA for PTEN or negative control siRNA AF 488 at a final concentration of $10 \mathrm{nM}$ using HiPerfect Transfection Reagent (Qiagen) according to the manufacturer's instructions. The cells were lysed $48 \mathrm{~h}$ post-transfection, resolved by $10 \%$ SDS-PAGE, transferred, and immunoblotted as described above. The $24 \mathrm{~h}$ post-transfected cells were cultured with or without $100 \mathrm{ng} / \mathrm{ml}$ IGF1 for the next $24 \mathrm{~h}$ for a BrdU cell proliferation assay as described above. 


\section{Statistical analysis}

One-way repeated measures ANOVA with Bonferroni correction or Dunnet's post test and the Student $t$-test using the raw data was used to determine the differences in BrdU cell proliferation assay, quantitative RT-PCR and densitometric analysis of western blotting. The fold-changes were calculated by dividing the treatment values by the control value in each experiment to present the results in the graphs. All statistical analyses were performed using SigmaStat for Windows version 2.0 (Systat Software Inc., San Jose, CA, USA).

\section{Declaration of interest}

The authors declare that there is no conflict of interest that would prejudice the impartiality of this scientific work.

\section{Funding}

This work was supported in part by a Grant from the 24th General Assembly of the Japanese Association of Medical Sciences.

\section{Acknowledgements}

We acknowledge the technical assistance of Yoshinari Nagatomo, B S for cell culture and western blotting.

\section{References}

Anderson GP \& Bozinovski S 2003 Acquired somatic mutations in the molecular pathogenesis of COPD. Trends in Pharmacological Sciences 24 71-76.

Baker J, Hardy MP, Zhou J, Bondy C, Lupu F, Bellve AR \& Efstratiadis A 1996 Effects of an Igf1 gene null mutation on mouse reproduction. Molecular Endocrinology 10 903-918.

Bencomo E, Perez R, Arteaga MF, Acosta E, Pena O, Lopez L, Avila J \& Palumbo A 2006 Apoptosis of cultured granulosa-lutein cells is reduced by insulin-like growth factor I and may correlate with embryo fragmentation and pregnancy rate. Fertility and Sterility 85 474-480.

Cantley LC \& Neel BG 1999 New insights into tumor suppression: PTEN suppresses tumor formation by restraining the phosphoinositide 3-kinase/AKT pathway. PNAS 96 4240-4245.

Das S, Maizels ET, DeManno D, St Clair E, Adam SA \& Hunzicker-Dunn M 1996 A stimulatory role of cyclic adenosine $3^{\prime}, 5^{\prime}$-monophosphate in follicle-stimulating hormone-activated mitogen-activated protein kinase signaling pathway in rat ovarian granulosa cells. Endocrinology 137 967-974.

Datta SR, Dudek H, Tao X, Masters S, Fu H, Gotoh Y \& Greenberg ME 1997 AKT phosphorylation of BAD couples survival signals to the cell-intrinsic death machinery. Cell 91 231-241.

Froment P, Bontoux M, Pisselet C, Monget P \& Dupont J 2005 PTEN expression in ovine granulosa cells increases during terminal follicular growth. FEBS Letters $\mathbf{5 7 9} 2376-2382$.

Gericke A, Munson M \& Ross AH 2006 Regulation of the PTEN phosphatase. Gene 374 1-9.

Goto M, Iwase A, Ando H, Kurotsuchi S, Harata T \& Kikkawa F 2007 PTEN and AKT expression during growth of human ovarian follicles. Journal of Assisted Reproduction and Genetics 24 541-546.

Gudermann T, Birnbaumer M \& Birnbaumer L 1992 Evidence for dual coupling of the murine luteinizing hormone receptor to adenylyl cyclase and phosphoinositide breakdown and $\mathrm{Ca}^{2+}$ mobilization. Studies with the cloned murine luteinizing hormone receptor expressed in $\mathrm{L}$ cells. Journal of Biological Chemistry 267 4479-4488.
Guthrie HD, Garrett WM \& Cooper BS 1998 Follicle-stimulating hormone and insulin-like growth factor-I attenuate apoptosis in cultured porcine granulosa cells. Biology of Reproduction 58 390-396.

Guzeloglu-Kayisli O, Kayisli UA, Al-Rejjal R, Zheng W, Luleci G \& Arici A 2003 Regulation of PTEN (phosphatase and tensin homolog deleted on chromosome 10) expression by estradiol and progesterone in human endometrium. Journal of Clinical Endocrinology and Metabolism 88 5017-5026.

Hu CL, Cowan RG, Harman RM \& Quirk SM 2004 Cell cycle progression and activation of AKT kinase are required for insulin-like growth factor I-mediated suppression of apoptosis in granulosa cells. Molecular Endocrinology 18 326-338.

Iwase A, Ando H, Nagasaka T, Shibata D, Harata T, Shimomura Y, Goto M \& Kikkawa F 2006 Neutral endopeptidase expressed by decidualized stromal cells suppresses AKT phosphorylation and deoxyribonucleic acid synthesis induced by endothelin-1 in human endometrium. Endocrinology 147 5153-5159.

Johnson AL, Bridgham JT \& Swenson JA 2001 Activation of the AKT/protein kinase B signaling pathway is associated with granulosa cell survival. Biology of Reproduction 64 1566-1574.

Kulik G, Klippel A \& Weber MJ 1997 Antiapoptotic signalling by the insulin-like growth factor I receptor, phosphatidylinositol 3-kinase, and AKT. Molecular and Cellular Biology 17 1595-1606.

Leslie NR \& Downes CP 2004 PTEN function: how normal cells control it and tumour cells lose it. Biochemical Journal 382 1-11.

Maehama T \& Dixon JE 1998 The tumor suppressor, PTEN/MMAC1, dephosphorylates the lipid second messenger, phosphatidylinositol 3,4,5-trisphosphate. Journal of Biological Chemistry 273 13375-13378.

Monniaux D \& Pisselet C 1992 Control of proliferation and differentiation of ovine granulosa cells by insulin-like growth factor-I and folliclestimulating hormone in vitro. Biology of Reproduction 46 109-119.

Moor RM, Dai Y, Lee C \& Fulka J Jr 1998 Oocyte maturation and embryonic failure. Human Reproduction Update 4 223-236.

Mutter GL, Lin MC, Fitzgerald JT, Kum JB \& Eng C 2000 Changes in endometrial PTEN expression throughout the human menstrual cycle. Journal of Clinical Endocrinology and Metabolism 85 2334-2338.

Poretsky L, Cataldo NA, Rosenwaks Z \& Giudice LC 1999 The insulinrelated ovarian regulatory system in health and disease. Endocrine Reviews 20 535-582.

Quirk SM, Cowan RG, Harman RM, Hu CL \& Porter DA 2004 Ovarian follicular growth and atresia: the relationship between cell proliferation and survival. Journal of Animal Science $\mathbf{8 2}$ E40-E52.

Richards JS, Russell DL, Ochsner S, Hsieh M, Doyle KH, Falender AE, Lo YK \& Sharma SC 2002 Novel signaling pathways that control ovarian follicular development, ovulation, and luteinization. Recent Progress in Hormone Research 57 195-220.

Rimon E, Sasson R, Dantes A, Land-Bracha A \& Amsterdam A 2004 Gonadotropin-induced gene regulation in human granulosa cells obtained from IVF patients: modulation of genes coding for growth factors and their receptors and genes involved in cancer and other diseases. International Journal of Oncology 24 1325-1338.

Roberts CT Jr 1996 Control of insulin-like growth factor (IGF) action by regulation of IGF-I receptor expression. Endocrine Journal 43 S49-S55.

Ryan KE, Casey SM, Canty MJ, Crowe MA, Martin F \& Evans AC 2007 AKT and Erk signal transduction pathways are early markers of differentiation in dominant and subordinate ovarian follicles in cattle. Reproduction 133 617-626.

Sasson R, Rimon E, Dantes A, Cohen T, Shinder V, Land-Bracha A \& Amsterdam A 2004 Gonadotrophin-induced gene regulation in human granulosa cells obtained from IVF patients. Modulation of steroidogenic genes, cytoskeletal genes and genes coding for apoptotic signalling and protein kinases. Molecular Human Reproduction 10 299-311.

Seto-Young D, Zajac J, Liu HC, Rosenwaks Z \& Poretsky L 2003 The role of mitogen-activated protein kinase in insulin and insulin-like growth factor I (IGF-I) signaling cascades for progesterone and IGF-binding protein-1 production in human granulosa cells. Journal of Clinical Endocrinology and Metabolism 88 3385-3391.

Shiota M, Sugai N, Tamura M, Yamaguchi R, Fukushima N, Miyano T \& Miyazaki H 2003 Correlation of mitogen-activated protein kinase activities with cell survival and apoptosis in porcine granulosa cells. Zoological Science 20 193-201. 
Slot KA, Kastelijn J, Bachelot A, Kelly PA, Binart N \& Teerds KJ 2006 Reduced recruitment and survival of primordial and growing follicles in $\mathrm{GH}$ receptor-deficient mice. Reproduction 131 525-532.

Sumitomo M, Iwase A, Zheng R, Navarro D, Kaminetzky D, Shen R, Georgescu MM \& Nanus DM 2004 Synergy in tumor suppression by direct interaction of neutral endopeptidase with PTEN. Cancer Cell 5 67-78.

Westfall SD, Hendry IR, Obholz KL, Rueda BR \& Davis JS 2000 Putative role of the phosphatidylinositol 3-kinase-AKT signaling pathway in the survival of granulosa cells. Endocrine 12 315-321.

White ES, Thannickal VJ, Carskadon SL, Dickie EG, Livant DL, Markwart S, Toews GB \& Arenberg DA 2003 Integrin alpha4beta1 regulates migration across basement membranes by lung fibroblasts: a role for phosphatase and tensin homologue deleted on chromosome 10. American Journal of Respiratory and Critical Care Medicine 168 436-442.

Received 24 July 2008

First decision 11 September 2008

Revised manuscript received 11 February 2009

Accepted 18 February 2009 